\title{
MAGDA ARCE
}

\section{Presencia de Gabriela Mistral}

$P$ ARA hablar de Gabriela Mistral es necesario recorrer primero la geografía lírica de Chile. Mariano Latorre, novelista chileno contemporáneo en su obra La literatura de Chile descubre con mucho acierto las zonas poéticas dentro del territorio chileno, de norte a sur.

Comienza con la zona de Coquimbo, en el Norte, que se caracteriza por la angustia espiritual que produce en los poetas la observación del paisaje de contraste: el verdor de la huerta y la sequía. A esta primera zona pertenecen Carlos R. Mondaca, Manuel Magallanes Moure y nuestra Gabriela Mistrail.

La segunda zona entroncada en el Maule produce el matiz elegíaco en la poesía chilena. Una característica común une a los poetas de la cordillera de la costa: el amor a su tierra. Recordamos a Max Jara y a Carlos Acuña, este último, el intérprete más fino y directo del paisaje del Maule en la poesía. "No es la cordillera de la costa un lugar risueño, dice Mariano Latorre. Aspero el paisaje; la tierra pedregosa. El hombre reconcentrado y suspicaz. La vida difícil, limitada, trágica. Se desprende del bravío perfil de lomas y serranías, algo como un resentimiento melancólico. Los poetas del Maule participan de esta muda elegía de los cerros de la costa. Su sensibilidad se alimenta del dolor de la tierra empobrecida, del hombre resignado". 1

La tercera zona nos trae la persistencia de la épica. Su centro: Concepción. Aquí están los poetas en cuyos versos la resonancia de Ercilla subsiste aún. Sus nombres: Diego Dublé Urrutia, Samuel A. Lillo.

\footnotetext{
- Latorre, Mariano. La literatura de Chile. Buenos Aires. Facultad de Filosofía y Letras de la Univ. de Buenos Aires, 1941, p. 174.
}

La cuarta zona, o sea, los poetas del sur, cuyo centro es Temuco, presenta un curioso fenómeno de renovación lírica. Temuco, tierra recién conquistada, ha dado a los poetas nacidos allá, la audacia revolucionaria y la riqueza emotiva. "La lucha constante del hombre de la conquista contra el medio hostil, agrega Mariano Latorre, el árbol centenario y el indio pertinaz, la antítesis del invierno gris y de los estíos de oro, hicieron del hachero, del colono y del mercader, hombres de acción, de ánimo decidido, cuyos problemas vitales debían resolverse en el momento mismo en que se presentaban. Era, por lo demás, tierra de porvenir, bravía y delicada". 2

Estos poetas del sur, descendientes de esos hacheros, de esos colonos, emigrados a las nuevas ciudades no vieron esa vida empenachada de epopeya. La vieron con un sentido original, rotos ya los lazos de la tradición, pero ahincados en el nuevo paisaje que sus descendientes crearon. Su más genuino representante es Pablo Neruda, otra figura poética, chilena, hispánica y universal.

Después viene la poesía moderna santiaguina cuyo centro es la capital, Santiago, con Pedro Prado, Angel Cruchaga Santa María, Juan Guzmán Cruchaga, Vicente Huidobro, líricos puros de fértil imaginación y dominio del idioma.

Gabriela Mistral, la ganadora del Premio Nobel de Literatura en 1945 , nació en Vicuña, pequeño pueblo de la provincia de Coquimbo, el 6 de Abril de 1889. Su nombre en aquel entonces era Lucila Godoy Alcayaga. Años más tande comienza a surgir en el nombre de las letras el nombre adoptivo de Gabriela Mistral.

\footnotetext{
3 Latorre, Mariano, Op. cit., p. 186.
} 
Hija de profesor, desde temprana edad la futura poetisa siente atracción por el magisterio. Es la única herencia que le ha dejado su padre: la bella vocación de maestra. Oigamos su Oración de la maestra: ${ }^{3}$

¿Señor! Tú que enseñaste, perdona que yo enseñe; que lleve el nombre de maestra que Tú llevaste por la Tierra.

Dame el amor único de mi escuela; que ni la quemadura de la belleza sea capaz de robarle mi ternura de todos los instantes.

Maestro, hazme perdurable el fervor y pasajero el desencanto. Arranca de mi este impuro deseo de justicia que aún me turba, la mezquina insinuación de protesta que sube de mí cuando me hieren.

No me duela la incomprensión ni me entristezca el olvido de las que enseño.

Dame el ser más madre que las madres, para poder amar y defender como ellas lo que no es carne de mis carnes. Dame que alcance a hacer de una de mis niñas mi verso perfecto y a dejarte en ella clavada mi más penetranle melodía, para cuando mis labios no canten más.

Muéstrame posible tu Evangelio en mi tiempo, para que no renuncie a la batalla de cada día y de cada hora por él.

En 1904, a los 15 años, es designada ayudante de una escuela rural ubicada en La Compañia, cerca de Coquimbo. Es por ese tiempo cuando comienza a escribir. Siente el lilamado de las letras. Publica varios artículos en la prensa de La Serena y cuando quiere ingresar a la Escuela Normal no puede hacerlo, porque sus artículos, considerados demasiado libres, le impiden el acceso a la Escuela. Empieza ya a despertar su potente personalidad, y su vida de lucha, que es como un símbolo de esperanza.

Más de algún biógrafo refiere en esta época su idilio con Romelio Ureta, joven de 25 años que terminó en suicida. Esta tragedia amorosa -más románticamente sentida que vivida quizás-imprime honda huella en el alma de nuestra poetisa. $Y$ así lo expresan sus versos:

\section{Todo adquiere en mi boca un sabor persistente de lágrimas; el manjar cotidiano, la trova $y$ hasta la plegaria 4.}

(Coplas).

3 Mistral, Gabriela. Desolacion. Santiago, Chile, Ed. del Pacífico, S. A. (1954). P. 197.

4 Mistral, Gabriela. Op. cit., p. 146.
Yo me olvidé que se hizo

tu pie ligero,

$y$, como en los buenos tiempos,

sali a encontrarte al sendero.

Pasé valle, llano y ró

y el cantar se me hizo triste.

La tarde volcó su vaso

de luz jy tú no viniste! ${ }^{5}$.

(La espera inútil).

En 1910 rinde exámenes en la Escuela Normal de Santiago. Un año después es Profesora del Liceo de Niñas de Traiguén y se abre entonces para ella la carrera del profesorado secundario. En 1911 y 1912 es Profesora del Liceo de Niñas de Antofagasta. Desde esta época hasta 1918, en el Liceo de Niñas de Los Andes.

Estos años marcan un paso decisivo en su carrera literaria. Allí está Gabriela Mistral cuando se celebran en Santiago los Juegos Florales de 1914. Ella envía a este certamen literario sus famosos Sonetos de la Muerte y recibió la más alta recompensa. Hay más de alguien que dice que Gabriela Mistral escuchó la ovación a sus Sonetos desde la galería del teatro.

Escuchemos el acento y la emoción de sus Sonetos de la Muerte: ${ }^{6}$

Del nicho helado en que los hombres te pu-

te bajaré a la tierra humilde y soleada. [sieron, Que he de dormirme en ella los hombres no [supieron y que hemos de soñar sobre la misma almoLhada.

Su fama se esparce en el acto por la nación entera. El año 1918 marca la trayectoria educacional y la tenemos de Directora del Liceo de Niñas de Punta Arenas, Magallanes; 1920-1921, Profesora del Liceo de Temuco; 1922, Profesora del Liceo de Niñas $N^{\circ} 6$ de Santiago.

Hacia 1922 su fama se extiende por el continente americano y el Gobierno de México la invita como huésped de honor. Recibe del Gobierno de México la misión de redactar una obra de lectura para los establecimientos femeninos de segunda enseñanza y así nace su obra Lecturas para Mujeres, editadas en Mé-

s Mistral, Gabriela. Op. cit., p. 143.

- Mistral, Gabriela. Op. cit., p. 139. 
xico y en Madrid. Es en la República Mexicana en donde ve desfilar emocionada a cinco mil niños cantando sus Rondas. ${ }^{7}$

\section{RONDAS DE NIÑOS}

\begin{abstract}
Las madres contando batallas
- sentadas estan al umbral. Los niños se fueron al campo, la roja amapola a cortar.
\end{abstract}

$Y$ asiste a la inauguración de su propia estatua en el patio principal de una escuela bautizada con su nombre. Así el espíritu de México rinde su mejor homenaje de admiración.

En 1924 hace su primer viaje a Europa. El Gobierno la distingue con una jubilación, por decreto-ley, como caso excepcional en mérito a sus trabajos literarios. En 1925 un nuevo viaje a Europa la Hleva como Delegado de Chile al Instituto de Cooperación Intelectual de la Liga de las Naciones en Ginebra, nombrada por el Gobierno. Viaja por Francia e Italia y en 1930 viene a los Estados Unidos. Retorna al magisterio, esta vez, dando conferencias sobre Literatura Chilena y Americana en Barnard College y Middlebury College. Recorre después Centro América y las Antillas donde es muy agasajada. Dicta una cátedra de Literatura Hispanoamericana en la Universidad de Puerto Rico. En La Habana desarrolla un curso de conferencias, lo mismo en Panamá.

El año 1932 marca la iniciación de Gabriela Mistral dentro de la carrera consular chilena, al designarla el Gobierno de Chile, Cónsul particular de elección en Génova. En 1933 es Cónsul en Madrid. Luego pasa a Lisboa, Río de Janeiro, $\mathrm{y}$ después, por varios años, reside en la bella ciudad de Petrópolis, Brasil.

Mientras desempeñaba dichas funciones y en atención a la espléndida labor cultural por ella desarrollada, el gobierno de Chile obtuvo del Congreso la dictación de una ley, promulgada el 24 de septiembre de 1935, que creaba especialmente para la poetisa un cargo permanente de Cónsul de Profesión siendo así el único funcionario consular que desempeñaba sus tareas en virtud de una ley especial.

\footnotetext{
'Mistral, Gabriela. Op. cit., p. 109.
}

En octubre de 1935 fué destinada a Lisboa en misión de propaganda y en 1936 viajó a Oporto y Guatemala con idénticos fines. En este último país tuvo el rango de Encargado de Negocios y Cónsul General.

En diciembre de 1938 fué destinada como Cónsul en Niza. Ese mismo año publicó en Buenos Aires, con la cooperación de Victoria Ocampo, su obra Tala (Ed. Sur) en donde vació toda la madurez de su producción poética.

En enero de 1940 fué trasladada a $\mathrm{Ni}$ teroi (Brasil) y un año después a $\mathrm{Pe}$ trópolis en donde la sorprendió, en noviembre de 1945, 1a consagración máxima a que puede aspirar un escritor: El premio Nobel de Literatura. El 10 de diciembre del mismo año recibe de manos del Rey Gustavo V de Suecia el preciado galardón en mérito a su obra literaria.

Desde 1945 en adelante se traslada a los EE. UU. en donde reside los últimos años de su vida. En efecto, el 17 de diciembre de 1945 es nombrada Cónsul de Chile en Los Angeles (EE. UU. de N. A), ciudad en que permanece hasta el año 1950, fecha en que se embarca en Nueva York, con rumbo a Génova, designada Cónsul de Chile en Nápoles. En 1953 parte a servir el Consulado de Chile en Nueva York y participa en la Asamblea General de las NU como Delegada de Chile.

En septiembre de 1954 llega a Chile invitada por el Gobierno del Presidente Ibáñez y permanece en el país recibiendo fervorosos homenajes hasta octubre del mismo año, fecha en que regresa a Nueva York. El año 55 el gobierno le acuerda una pensión especial por medio de una ley que se promulga en noviembre de 1956.

El 20 de diciembre de 1956 la prensa anuncia que se encuentra enferma de cuidado y el 5 de enero de 1957 el cable informa la suma gravedad de su dolencia, en el Hospital de Hempstead de Long Island, Nueva York.

En la madrugada del 10 de enero de 1957, fallece.

Con fecha 19 de enero llegan sus restos a Chile y son instalados en el Salón de Honor de la Universidad de Chile. Más de 200 mil personas desfilan por la 
Casa Universitaria ante su féretro, en mudo homenaje a la gran poeta de Chile.

El día 22 de enero es sepultada transitoriamente, en el Cementerio General de Santiago, mientras se construye un mausoleo en la aldea nortina de Montegrande.

Gabriela Mistral es la primera figura literaria de Chile y una de las más altas autoridades morales del continente americano. Su obra poética se compone de cuatro volúmenes de poesias: Desolación, publicado en Nueva York en 1922, por el Instituto de las Españas de CoIumbia University y a insinuación del ilustre catedrático español, amigo y maestro, don Federico de Onís. Ternura, colección de poemas infantiles y canciones de cuna, publicado en Madrid en 1924. Tala, publicado en Buenos Aires en 1938. Lagar, publicado en Chile, por la Editorial del Pacífico.

"Mis maestros en el arte para regir la vida, dice Gabriela Mistral, son: la Biblia, el Dante, Tagore y los rusos. Mis grandes amores son: la fe, la tierra, la poesía". 8

"En su verso, dice el crítico chileno Armando Donoso, ${ }^{9}$ el don lírico tiene una armoniosa resonancia de copla; fluye de una desprevenida entonación de canto y de una necesaria forma expresiva".

¿Es su poesía un eco de sus sentimientos íntimos o una pura efusión literaria?

A esta pregunta podemos responder trazando a grandes rasgos la representación emotiva del poeta. Hallamos en su poesía los siguientes elementos: idea de eternidad, sentimiento de la naturaleza, Dios, embriaguez divina, elocuencia en el dolor, sensibilidad, inquietud de la muerte, sentimiento del amor y de la vida lírica, idealidad, emoción bíblica, gracia en el verso, desesperación mística, predilección por las metáforas realistas, sentido de la maternidad, la imagen novedosa y expresiva, el verso múltiple, ternura.

Gabriela Mistral se nos muestra como un realista cuyo fondo de verdad huma-

8. Silva Castro, Raúl. Estudios sobre Gabriela Mistral, Santiago, Zig-Zag, 1935. P. 8.

- Donoso, Armando. La otra América. Madrid, Calpe, 1925. IP. 39. na trasciende en todas sus emociones, que el verso recoge en su forma reciamente masculina. Un sentido real de las cosas y el hervor tumultuoso de la vida animan su verso. Place en este lírico su tranquila conformidad, su resignada fe, su voluntad que deriva hacia el amor. "Entonación de plegaria, es su verso" dice el poeta ecuatoriano Jorge Carrera Andrade. Intensidad, inquietud de intensidad en su verso, agregamos nosotros.

El amor en los versos de la Mistral tiene toda su grandeza real y toda su desesperación humana. Escuchémosla:

\section{AMO AMOR ${ }^{10}$}

Anda libre en el surco, bate el ala en el viento, late vivo en el sol $y$ se prende al pinar.

No te vale olvidarlo como el mal pensamiento: ile tendrás que escuchar!

Si yo te odiara, mi odio te daría en las palabras, rotundo y seguro; pero te amo $y$ mi amor no se confía a este hablar de los hombres, tan oscuro! ${ }^{11}$.

(El amor que calla)

Ahora Cristo, bájame los párpados pon en la boca escarcha, que están de sobra ya todas las horas $y$ fueron dichas todas las palabras ${ }^{12}$.

(Extasis).

Señor, Tú sabes cómo, con encendido brío, por lós seres extraños mi palabra te invoca. Vengo ahora a pedirte por uno que era mío, mi vaso de frescura, el panal de mi boca ${ }^{13}$.

(El ruego).

Desolación, antes que un libro plácido es una obra de sufrimiento interior. Es su primer libro. "Si es grande y nobilísima la parte imaginativa de su obra, no to es menos la que se refiere a su novedosa variedad prosódica", dice Armando Donoso, ${ }^{14}$ crítico chileno; "toda la lira cabe en su verso espléndido".

Usa la imagen porque tal vez nada establece una correspondencia más directa entre la sensibilidad y la observación, corazón y pupila, que llega a ser como elemento decorativo indispensable. Sus formas métricas proceden de la más estricta tradición castellana. Es el más in-

10 Mistral, Gabriela. Op. cit., p. 123.
${ }_{11}$ Mistral, Gabriela. Op. cit., p. 124.
${ }_{12}$ Mistral, Gabriela. Op. cit., p. 125.
${ }_{14}$ Mistral, Gabriela. Op. cit., p. 154. 
dependiente de los líricos, aunque ni en su lenguaje ni en su estrofa jamás la libertad se convirtió en licencia.

Repetimos con Armando Donoso, Desolación su primer volumen, obra esencial de madurez, representa lo mejor en su labor literaria. Nada denuncia en ella los comienzos: el poeta aparece dueño de sus recursos líricos y maduro en sus ideas.

La crítica chilena e hispanoamericana la ha acogido con la más cordial bienvenida y saludo espiritual. Oigamos la voz de algunos críticos autorizados que juzgan, con justicia, la obra poética de Gabriela Mistral:

Mariano Latorre, dice: "La poesía de Gabriela Mistral es la revelación de un temperamento originalísimo que busca la verdad analizando su drama íntimo. Poesía de un extraordinario sabor de vida, agonía dolorosa de pedir y no recibir lo que se pide. Primero el amor, la maternidad después, fundidas en su vocación de maestra y que se va elevando, poco a poco, en una plegaria mística de penetrante sinceridad". 15

Tomás Gatica Martínez dice: "La firme y rica estructura psíquica de Gabriela Mistral está expresada en su poesía. En ella hay, comprensión genial, gigantesca manera de sentir, de amar, de padecer. Luego, la palabra tensa como un vendaval; encendida como un ascua; amarga y salada como el mar, sedante y dulce como la miel". 16

Hernán del Solar dice: "Una alabanza sin doble faz le dió la bienvenida. Era un acento nuevo el suyo. Nunca el dolor había alcanzado tan humanamente igual desgarramiento en el grito, en el intervalo de silencio que luego estalla en súplica, en imprecación, en sollozo, para regresar a su estremecida taciturnidad... Con su haz de trenzados fatalismos, de ternuras desesperadas, de asperezas y suavidades, quedó sola entre dos generaciones; vigía única en el océano, fantasma de un universo nacido entre Dios y su alma". 17

${ }_{15}$ Latorre, Mariano. Op. cit., p. 171.

${ }^{10}$ Gatica Martínez, Tomás. Ensayos sobre literatura hispanoamericana. Santiago, Editorial Andes, 1930. P. 85.

17 Solar, Hernán del. Indice de la poesía chilena contemporánea. Santiago, Ercilla, 1937. (Biblioteca América). P. XVI.
Raúl Silva Castro dice: "Dentro de la poesía femenina de Hispanoamérica la obra de Gabriela Mistral se distingue por la castidad de su tono y la austeridad de la imaginación sobre todo en los asuntos eróticos: castidad y decoro". ${ }^{18}$

Julio Saavedra Molina dice: "Su lirismo hunde las raices en una tragedia vivida y en los sentimientos derivados. No es producto de la imaginación servida por una sensibilidad feliz; es la sensibilidad misma de una neurosis exteriorizada casi sin imaginación: es poesía y no arte de artífice". 19

"Desde Safo hasta la Agustini, las más grandes poetisas han cantado la alcoba feliz o inquieta, el amor cupídico, han sido sobre todo eróticas, individualistas, como cualquier Anacreonte, Cátulo, Petrarca, Ronsard o Byron, sin llegar a la excelencia de éstos y de tantos otros que dijeron las cuitas de Eros o sus neurosis, sin pensar en la especie. Tales poetisas siguieron atajos masculinos y se mostraron con inspiración refleja, asexuada. Gabriela Mistral, al revés, ha interpretado lo que hay de genuino en su sexo, transformando sus sensaciones y sentimientos femeniles en materia poética. Era una vena inexplorada e inexplotada; al hallarla y laborarla ha sido genial". 20

El eminente crítico español, catedrático de Columbia University en New York y actualmente encargado del Departamento de Estudios Hispánicos, de la Universidad de Puerto Rico, Federico de Onís, dice: "En todo lo que hace muestra una natural superioridad, $y$ en todo lo que toca deja profunda huella. Avanza con un aire de reposo y serenidad milenarios; su voz suena quejumbrosa, igual y distante, con matices de dureza y de dulzura difíciles de imaginar; la contracción dolorosa de su boca se deshace en una sonrisa de infinita suavidad. Alma tremendamente apasionada, grande en todo, después de vaciar en unas cuantas poesías el dolor de su desolación íntima, ha llenado ese vacío con sus preocupaciones por la educación de los niñ̃os, la redención de

18 Silva Castro, Raúl. Op. cit., p. 28.

10 Saavedra Molina, Julio. Gabriela Mistral. Vida y obra. En Revista Hispánica Moderna. New York, Columbia University, No 2, año III, Enero 1937, P. 116. 133.
${ }^{20}$ Saavedra Molina, Julio. Op. cit., pp. 132. 
los humildes y el destino de los pueblos hispánicos. Todo esto en ella no son más que otros modos de expresión del sentimiento cardinal de su poesía; su ansia insatisfecha de maternidad, que es a la vez instinto femenino $\mathrm{y}$ anhelo religioso de eternidad. Las fuentes de su arte literario, demasiado próximas y visibles, son indiferentes ante la magnitud e intensidad de su pasión, que encuentra siempre, a través de no se sabe qué esfuerzos recónditos, la justeza de la expresión en las palabras de sabor más íntimo y universal de la lengua casteIlana". 21

El ensayista cubano Jorge Mañach con aguda penetración dice: "La compenetración del sentido del Espíritu y el sentido de la Materia, de la emoción de Dios y de la Naturaleza, de la inquietud de la Muerte y la inquietud de la Carne, rige toda su intimidad poética y hasta su misma forma expresiva. Un temblor religioso y un temblor voluptuoso la estremecen a la par. El ansia de eternidad se plasma en la adoración de lo divino; el ahinco de la materia en una ternura insaciable hacia toda naturaleza". ${ }^{22}$

Del cristianismo tiene el amor de la pobreza cuyo elogio hace en varias formas; ha vivido pobre y ha estado siempre al lado de los humildes, con una sinceridad que conmueve. También es cristiano su culto del dolor.

Ama a las criaturas débiles y en especial a los niños. Canta a la infancia con singular candor. Comprende que la infancia es el capital humano potencial que constituye el recurso más valioso de toda nación. Y es a esta infancia a quien ella dedica sus Rondas infantiles, las canciones de cuna. Elogia las manos infantiles, el beso tierno de los niños, los pies desnudos. Oigámosla de nuevo, con fervorosa unción:

"Onís, Federico de. Antología de la poesía española e hispanoamericana. (1882-1932). Madrid, Centro de Estudios Históricos, 1934. Págs. 920-21.

23 Mañach, Jorge. Gabriela: alma y tierra. En Revista Hispánica Moderna. New York, Columbia University, No 2, año III. Enero 1937. P. 107.

\section{$D U L Z U R A{ }^{28}$}

\author{
Madrecita mía \\ madrecita tierna, \\ dejame decirte \\ dulzuras extremas.
}

\author{
Piececitos de niño \\ azulosos de frio \\ icómo os ven y no os cubren, \\ Dios mío!
}

(Piececitos) 24

\begin{abstract}
Madre, madre, tú me besas; pero, yo te beso más. Como el agua en los cristales son mis besos en tu faz.
\end{abstract}

(Caricia) ${ }^{25}$

Con todo acierto, repetimos con Alejandro Gumucio: ${ }^{26}$ "Es una madre en potencia con todo el ardor de la ternura $y$ del sacrificio $y$ es hermoso todo aquello que dice a los hijos que no tuvo y que, sin embargo, sienta en sus rodillas, acaricia y les habla en el más sublime de los idiomas".

\section{CANCIONES DE CUNA $"$ "}

Velloncito de mi carne -que en mi entraña [yo tejivelloncito friolento - duérmete apegado a mí La perdiz duerme en el trébol -escuchándole Ilatir: no te turbes por mi aliento -duérmete apeIgado a mi.

(Apegado a $\mathrm{mi}$ ).

Ama, asimismo, a las mujeres, a las abandonadas e incomprendidas, a la madre soltera, a la maestra rural y a la hembra fuerte de la Biblia. Y en este recordatorio simbólico de la poesía de la Mistral podemos repetir con ella sus versos a:

\section{LA MUJER FUERTE}

Me acuerdo de tu rostro que se fijo en mis mujer de saya azul $y$ de tostada frente, que en mi niñez y sobre mi tierra de ambrosía vi abrir el surco en un abril ardiente.

${ }^{23}$ Mistral, Gabriela. Op. cit., p. 106.

${ }^{24}$ Mistral, Gabriela. Op. cit., p. 79.

26 Mistral, Gabriela. Op. cit., p. 105.

* Gumucio, Alejandro. Gabriela Mistral y el Premio Nobel. Santiago, Ed. Nascimento, 1946. P. 22.

${ }^{27}$ Mistral, Gabriela. Op. cit., p. 209.

ss Mistral, Gabriela. Op. cit., p. 40. 
La mujer que no mece un hijo en el regazo, cuyo calor y aroma alcance a sus entrañas, tiene una laxitud de mundo entre los brazos; todo su corazón congoja inmensa baña.

(La mujer estéril) ${ }^{20}$.

La maestra era pura. "Los suaves hortelanos", decía "de este predio, que es predio de Jesús, han de conservar puros los ojos y las manos, guardar claros sus óleos, para dar clara luz".

(La maestra rural) ${ }^{80}$.

Esta es Gabriela Mistral, que recibió el más alto homenaje literario del mundo: el Premio Nobel de Literatura en 1945.

"The New World has been honored through me - ha dicho Gabriela Mistral al saber el premio, the victory is not mine but America's". 31

"El triunfo no es sólo mío sino de América", de esta América que ella tanto ama y que define con singular exactitud: "Tierra mágica como ninguna es la tierra americana... como los arcángeles persas, es de una potencia que casi hiere, que casi mata; ella nos embriaga, nos arrebata y nos purifica violentamente, ya sea por agua, por vientos o por soles". 32

Me he aproximado tres veces a Gabriela Mistral. En 1938, en Nueva York, en 1942 en Petrópolis, Brasil, y en 1954 también en Nueva York. Era yo estudiante de Literatura en Columbia University y en el recinto universitario supimos de la llegada a Nueva York de Gabriela Mistral. Un distinguido intelectual venezolano que en ese entonces estudiaba allí también, Felipe Massiani, y yo decidimos llegar hasta ella para expresarle nuestros sentimientos de admiración y simpatía.

Felipe Massiani que era amigo personal de Gabriela Mistral, le telefoneó una tande y nos recibió en la residencia de una dama chilena, la Sra. Elisa Parada de Miguel, en donde se hospedaba. Alilí a la hora del té pudimos gozar de su conversación y de su presencia. Yo

29 Mistral, Gabriela. Op. cit., p. 41.

so Mistral, Gabriela. Op. cit., p. 69.

Revista Time. New York, noviembre 26, 1945. P. 40.

32 Palabras conservadas en mi memoria, al leer una entrevista a Gabriela Mistral en un perí́dico de Río de Janeiro, Brasil, en 1942. estaba muy emocionada. Era la primera vez que la conocía personalmente, después de leerla desde niña en mis libros de lectura, y más tarde en la Universidad. Recuerdo que con emoción estreché sus manos mientras Massiani procedía a la tarea de la presentación: "La Srta. Magda Arce, chilena y estudiante de Literatura en Columbia University". Casi no hablamos por escucharla. Fueron tres horas de alegría espiritual muy honda ... Nos habló de España, de sus viajes y de poesía. Nunca me olvido de sus palabras acogedoras y de su simpatía y bondad al despedirnos. Nos acompañó hasta el ascensor, y mientras yo tropezaba al entrar, le dijo a Massiani sonriendo: "Adiós y cuídeme mucho a la chilenita".

Más tarde, en 1942 y con motivo de un viaje al Brasil realizado bajo los auspicios de la Cooperación Intelectual del Ministerio de Relaciones Exteriores de Brasil llegué a ese gran país y quise verla. Varias veces traté de alcanzar a Petrópolis, pero siempre hubo algún inconveniente que me impidió hacerlo con más anticipación. Quería terminar mi misión cultural en Río y demás partes del Brasil y dejar tres días enteros para dedicarlos a una larga visita a Petrópolis y a Gabriela Mistral. La prioridad del avión -era en tiempos de guerra- hizo que mi viaje de regreso a Chile se modificara de repente y sólo tuve el tiempo de ir a Petrópolis el día antes de salir para Chile. Mi presentación, para ella, era esta vez, mi primer trabajo literario sobre el novelista chileno contemporáneo Mariano Latorre, publicado en México y en Columbia University, y una carta de presentación de la escritora chilena y en aquel entonces Cónsul en La Plata, Marta Brunet.

No encontré a Gabriela Mistral. Sin embargo me atendió su sobrino, que, desgraciadamente, supe después, terminó en suicida.

Le dejé unas líneas a la gran poeta de Chile y para que me recordara mejor le mencioné la visita en Nueva York y sus palabras a Massiani. Semanas más tarde y ya estando en Santiago, recibí una carta de Gabriela Mistral, que todavía conservo. Dice así: 
Petrópolis, s/f. 1943.

\section{Distinguida paisana:}

He recibido la fina carta que dignó Ud. dejar en la Oficina. Por el juego de esos espíritus burlones que, según dicen mis amigos teósofos, juegan con nosotros, Ud. no halló en casa a una mujer que es caserísima. Bajé a Ríos a cambiar un cheque de sueldo. Un agente nuevo de cambios exigió que yo firmase en presencia cosa que no había pasado antes.

En todo caso, dejó usted en la casa un admirador, mi sobrino, que me habló de usted con gran entusiasmo y alegría.

Tengo la experiencia de que en los viajes todo lo que se deja para el día penúltimo se malogra y usted dejó a Petrópolis para ese día, precisamente. Y Petrópolis es una ciudad que merece ser vista y con calma, pues es única en su género aquí en el Brasil. Yo la habría guiado por ella con la mejor voluntad.

No recuerdo su rostro, pero, es curioso, recuerdo la frase mía a Massiani que usted me cita en la casa de la Sra. Miguel.

He leído los dos trabajos suyos, tan preciosos y honrados en su factura, que se sirvió dejar para mí en la mesa. Me he alegrado de corazón saberla así de seria en su trabajo y con apercu tan lucidos sobre sus asuntos. Hágame llegar lo que siga haciendo. A pesar de la caída de mi vista, que me tiene ceñida a un régimen de 30 páginas a lo más de lectura diaria, yo me haré leer lo suyo, por seguir su bonita carrera y los asuntos de Chile.

Acaba de irse el señor Graca Aranha que vino a contarme de su visita, de lo que han tratado sobre cooperación intelectual y de su excelente impresión personal de usted. Le añadí mis bellas noticias suyas y quedo saboreando la buena nueva de que usted tendrá allá mil quinientos libros brasileros, que leerán en parte usted y su clientela de mozos.

Agradezco mucho a Marta Brunet la atención de habérmela presentado y mando esta carta por duplicado, a ella y a usted a Chile, es decir, por partida doble a fin de que llegue a sus manos.
Reciba usted los saludos afectuosos de su paisana y compañera adicta, que espera el que usted vuelva al Brasil.

Gabriela Mistral.

$\mathrm{Y}$ últimamente en 1954, en Nueva York, en la Sede de las Naciones Unidas, volví a encontrarme, por vez postrera, con Gabriela Mistral. Era una reunión social que nuestra Delegación a las NU ofrecía en homenaje a la ilustre poetisa. Al saludarla, estando ella en el "receivingline", junto a nuestro Embajador y Jefe de la Delegación, señor Rudecindo Ortega, don Carlos Dávila y otras personas recuerdo que me dijo cariñosamente: "En mi vida hay muchas caras sin nombres $y$ muchos nombres sin caras. Es curioso, de su rostro no me acuerdo, pero de su nombre, sí".

La noticia de su muerte nos sorprendió - como a todos-dolorosamente. Habíamos aprendido a admirarla, a quererla, a sentirla tan cerca. Junto a mi se hallaba esa noche mi pequeña hija Diana, de 8 años, que escuchaba también en la radio las palabras sobre la triste nueva. El recital de sus poemas dados a continuación, en la penumbra de nuestro hall, impresionó a la pequeña, quien también turbada por la emoción, con los ojos cerrados repetía en silencio:

"Piececitos de niño
Azulosos de frio
iComo os ven
$y$ no os cubren
Dios mio!

Hace pocos días, visitando Vicuña, llegamos a lla humilde casa donde nació Gabriela. Tierra que será santuario y adonde volveremos algún día muy calladamente en humilde y respetuosa peregrinación. Repetimos aquí, a guisa de oración, las palabras de un autor peruano que dan eternidad a la obra del artista: "La vida hay que vivirla de tal suerte que el ser quede vivo tras su muerte".

Santiago, Junio 3 de 1957. 